\title{
Relationship between the components of product/service quality and the customers' emotions and satisfaction
}

\author{
Gavriel Meirovich; Nisreen Bahnan \\ Salem State College (USA) \\ gmeirovich@salemstate.edu;nbabnan@salemstate.edu
}

Received September 2008

Accepted December 2008

\begin{abstract}
The purpose of this paper is to study the links between quality and consumers' emotions and eventually with their satisfaction. There is mounting evidence that, while quality evaluation may be strictly cognitive, satisfaction gauges customers' emotions towards the product/service provider's performance. The existing approaches used in measuring quality have certain limitations. This study introduces two components of total quality structure - quality of design and quality of conformance - for analysis of the link between quality and customer emotions. Undergraduate college students were surveyed in regard to four scenarios for food establishments. Respondents were asked to select, from a pre-tested list of emotions, those arising from these scenarios. The equality of means of the valence and the intensity of emotions among the four scenarios were tested using ANOVA and Scheffe paired comparisons. The results show that there is a significant relationship between possible combinations of two quality dimensions and customers' affective responses in terms of both their valence and intensity. Important managerial implications are discussed.
\end{abstract}

Keywords: design quality, conformance quality, emotions, satisfaction 


\section{Introduction}

This paper studies the links between quality and consumers' emotions and eventually with their satisfaction. The importance of quality and customer satisfaction is well documented in the literature (Oliver, 1996), and specific emphasis has been placed on these concepts within service encounters. In accordance with work in the customer satisfaction area (Oliver, 1981), researchers in service quality (Boulding et al., 1993; Parasuraman et al., 1991) argue that perceptions of quality are based on a customer's expectations about quality and the actual service delivered. Research on discussed concepts has been initially cognitive in nature, with both having been posited as post-consumption cognitive processes (Liljander \& Strandvik, 1997). However, there is mounting evidence that, while quality evaluation may be strictly cognitive, satisfaction gauges customers' feelings towards the service performance. When a product/service falls below consumers' expectations, they display negative emotions; if, on the other hand, the offering is perceived to meet or exceed expectations, customers respond with positive emotions. (Oliver, 1993b; Oliver \& Westbrook, 1993).

Despite the significant progress made in study of relationship between quality, customer emotions and satisfaction, certain gaps remain in the literature. Existing instruments of measuring quality do not possess discriminative ability in addressing specific emotions evoked by suppliers' offerings. In addition the most prevalent approaches such as SERVQUAL gauge pure service quality without covering product quality, which makes them limited. This paper introduces a new instrument in measuring product/service quality which seems to be more comprehensive and informative than the tools used so far in the analysis of the discussed relationship.

Satisfaction is related not only to the pleasantness (valence) of emotions but also to their intensity (arousal). The prominent Circumplex Model of Affect proposed by Russell (1980) integrates these two primary components of emotions into a useful and robust framework. Multiple dimensions of emotions, or dimensionality greater than two, although commonly found, tend to be unstable among samples and situations (Mano \& Oliver, 1993). Therefore, it is logical to maintain that any emotion that is analyzed in this paper in its relationship to quality can be classified in terms of its valence and intensity. 
Emerging emotions and their relationship with customer satisfaction depend on the attribution process, i.e. on the perceived cause of emotions (Dube \& Menon, 2000). For instance, anger is often exhibited in a complaint situation when the service failure can be attributed to the company (Oliver, 1996). In contrast, due to its inward orientation, sadness is more likely to be attributed to circumstances beyond the control of a provider (ibid). As a result sadness occurs less frequently in complaints than provider-attributed emotions such as anger. Since this study investigates the impact of a supplier's product/service quality on affective responses, it excludes internally attributed emotions.

The paper is organized as follows: We begin with the analysis of existing approaches to quality measurement in service encounters. Then, we introduce a new instrument which appears to be more informative in gauging quality and formulate specific research hypotheses regarding quality, customer emotions and satisfaction. Next, we present our method and empirical results. Finally, we provide a discussion of our findings and their implications.

\section{Approaches to quality measurement}

Existing literature on the effect of quality on customer satisfaction uses a few approaches in gauging quality. The most popular is the SERVQUAL tool (Parasuraman et al., 1991), which measures the difference between expectations and customer perceptions on five factors of service quality - tangibles, reliability, responsiveness, assurance, and empathy. Since subtracting perceptions from expectations raises issues of validity (Cronin \& Taylor, 1992; Teas, 1993) and psychometric inferiority (Peter et al., 1993), some authors suggest using customer perceptions alone (SERVPERF by Cronin and Taylor, 1992) in gauging perceived quality. Still others (Oliver, 1996; Teas, 1993) use a global assessment of quality, which is not based on performance attributes.

We believe that though there are virtues in all noted instruments, there are also certain limitations. Both SERVQUAL and SERVPERF measure service quality without covering product quality. So these instruments are limited to pure service; the quality of tangible products delivered in service such as retail store or restaurant cannot be properly analyzed. In order to get a comprehensive evaluation of quality in mixed product/service settings researchers and practical managers would need a 
parallel assessment of product quality as well, and from both methodological and operational standpoint, this can make a study too complicated.

Another limitation of this approach is that SERVQUAL and other similar tools do not possess discriminative ability that allows pinpointing the impact of each quality dimension or their combinations on different emotions. The best possible result that can be achieved using SERVQUAL in regard to customers' emotions is similar to other disconfirmation approaches (see Oliver, 1993a; Oliver \& Westbrook, 1993): positive disconfirmation leads to positive emotions whereas negative disconfirmation leads to negative emotions. It is unclear whether a certain dimension generates emotions characterized by high or low intensity. For instance, when tangibles or empathy are below customer expectations, what negative emotions do they trigger? Is it anger, annoyance, or boredom? By the same token, if assurance is above expectations, which positive emotions appear - delight, contentment, confidence? We may reverse the perspective and look at customers' emotions as symptoms of problems that a company experiences in its service. The symptoms are useful in that they provide external exposure to inefficiencies in organizational processes so that problems are dealt with sooner rather than later. If a manager observes customers who are irate (or confused, or anxious) - what signal does this send to her regarding SERVQUAL dimensions? Probably that some of them are unsatisfactory and need to be addressed. However it is difficult to pinpoint particular dimensions that are inadequate.

Discussed weakness is even more salient in the global metrics of quality. Overall indicators of quality, being not performance-based are useful for the general assessment of quality and its relationship with customer satisfaction and other constructs. Still they do not provide specific information about the specific emotions evoked by products/services. These drawbacks would be of less importance if quality and emotions were unrelated and had separate impacts on satisfaction, as argued in some studies (Kramph et al., 2003; Liljander \& Strandvik, 1997). But though independent impact of both phenomena on satisfaction might take place, it is reasonable to assert that there is a significant association between them. For example Oliver (1993a) showed that emotions mediate the link between perceived quality and satisfaction. A similar result was reported by Price et al. (1995). The authors found that customers' emotions completely mediated the relationship between provider's performance and 
customer satisfaction. These results suggest that there is the direct link between quality and emotions which is not sufficiently investigated in the literature.

In this study we introduce another instrument for analysis of the relationship between quality and customer emotions that seems to be more accurate and informative than tools used so far. The objective of our research involves two components of the total quality structure - quality of design and quality of conformance. As it will be shown later, there is a significant relationship between these dimensions, or more precisely, their combinations and customers' emotional responses in terms of their valence and intensity. Moreover, these metrics are more universal than SERVQUAL and may be used regardless of industry type.

\section{Quality dimensions: quality of design and quality of conformance}

Quality of design and quality of conformance are two elements of quality structure that complement and interact with each other. Quality of design is defined as product/service characteristics that suit customers' expectations, needs and wants (Gitlow et al., 2005; Meirovich, 2006; Widrick et al., 2002). Quality of conformance is a degree of product uniformity and fit to its specifications. The former component can be improved through marketing and R\&D activities, which introduce new attractive features and endeavor to match products to changing customer needs. The latter component is enhanced via continuous improvement in operations, which results in lower variation and a higher consistency of internal processes.

In order to match product features to different individual and group needs a company has to deliver a variety of products rather than a standardized product with an assumption that "one size fits all". Since customer needs and expectations constantly change, a company has to incorporate new features into a product and to upgrade existing features. Failure to introduce products with new or better characteristics does not lead to fixed level of design quality. When expectations and needs rise, a discrepancy between them and existing product features appears. As a result a product partly or totally loses its appeal. For instance, a patron of a restaurant who has lunch on the regular basis may become bored with the same meals that are offered time after time. The generation of a gap between expectations and characteristics of products means the reduction of quality of design even if a product did not change a bit (Meirovich, 2006). 
Better understanding of the process of losing design quality without altering a product can be achieved if we invoke a model developed by Kano (1984). According to this model all features can be divided into three categories: basic "must be' features, the low functionality of which makes a product inferior and unacceptable for customers; satisfiers, whose performance can create both dissatisfaction and satisfaction; and delighters that make a product highly attractive to customers and generate their satisfaction. Each product or service is a certain blend of these three groups. Division between categories is not static: due to growth of needs and expectations new attractive features over time become satisfiers and eventually basic, "must be" features. Consequently, an organization that does not change an assortment of its products is pushed backwards and is doomed to the gradual degradation of quality of design.

As far as the second component of total quality - quality of conformance - is concerned, in order to increase products' uniformity a company's staff should thoroughly analyze causes of variation, apply statistical process control (SPC) and other analytical tools so as to keep actual product attributes within specification limits. High quality of conformance implies doing things right the first time and keeping promises to customers. In contrast, low quality of conformance results in lack of consistency, multiple errors and defects.

Each quality dimension can be split into high and low values. Possible combinations of two dimensions with high and low values produce the following four-cell grid (Table 1). These combinations and commensurate emotions are described in the next section of the paper.

\begin{tabular}{|c|c|}
\hline $\begin{array}{c}\text { 1. High Conformance Quality } \\
\text { High Design Quality }\end{array}$ & $\begin{array}{c}\text { 4. Low Conformance Quality } \\
\text { High Design Quality }\end{array}$ \\
\hline $\begin{array}{c}\text { 2. High Conformance Quality } \\
\text { Low Design Quality }\end{array}$ & $\begin{array}{c}\text { 3. Low Conformance Quality } \\
\text { Low Design Quality }\end{array}$ \\
\hline
\end{tabular}

Table 1. "Combinations of quality dimensions". 


\section{Quality dimensions and customers' emotions}

It is reasonable to hypothesize that the combination of the values of two quality components in each cell of the grid tends to trigger a particular set of emotions in terms of their valence and intensity and certain level of customer satisfaction:

1. High quality of design and high quality of conformance. Undoubtedly this is the best possible situation for a company. The provider is ambidextrous and succeeds in both attuning its products to customer needs and supplying them in consistent fashion without making too many mistakes. A company is reliable and dependable; it keeps promises to customers regarding level of supplied product and service. Moreover, it is sufficiently responsive to special needs and apparently delivers a rich variety of products and services to accommodate different customers. The company's managers and employees know that one size does not fit all. Staff is innovative and creative in supplying new products and updating existing ones. Under these circumstances customers are highly satisfied and it is unlikely that customers will experience negative emotions. We can expect that emotions will be characterized both by positive valence and a high level of arousal. Consequently, we can formulate the hypotheses:

Hypothesis 1a. High quality of design and high quality of conformance are associated with experiencing intense positive emotions (e.g. delighted).

Hypothesis $1 \mathrm{~b}$. High quality of design and high quality of conformance are associated with high customer satisfaction.

2. Low quality of design and high quality of conformance. This is a moderately favorable situation for a provider. Level of product and service is consistent and predictable; customers know exactly what to expect. They do not anticipate pleasant or unpleasant surprises. Mistakes and defects are few and promises are implemented, so there is no reason for customers to be anxious or angry. At the same time there is nothing exciting or thrilling about this service - one get the same standardized offering over and over again. Customers are calm and to a certain degree bored. (Oliver, 1996: 327). Customer satisfaction is not as high as it is in the previous scenario. We can formulate the following hypotheses: 
Hypothesis 2a. Low quality of design and high quality of conformance are associated with experiencing low intensity and neutral tending towards the positive valence of emotions (e.g. relaxed, bored).

Hypothesis $2 b$. Low quality of design and high quality of conformance are associated with a moderate level of customer satisfaction.

3. Low quality of design and low quality of conformance. This is obviously the worst possible situation for a provider. Products and services fail to match customers' needs. The company is perceived as neither reliable nor responsive. There are many mistakes and defective products due to haphazard, unstable processes with high variation. Level of service is unpredictable, consequently customers do not know what to expect, and they are nervous and frustrated. Buyers cannot find what they want because they do not have many choices. Special requests are ignored or disregarded. The provider exaggerates his promises and is not able to keep them. When talking with different employees customers get different answers to the same questions. It can be expected that customers will experience intensive negative emotions, and their satisfaction will be low. Consequently, we can formulate the hypotheses:

Hypothesis 3a. Low quality of design and low quality of conformance are associated with experiencing intensive negative emotions (e.g. angry).

Hypothesis $3 b$. Low quality of design and low quality of conformance are associated with low customer satisfaction.

4. High quality of design and low quality of conformance. The company is very innovative and rapidly develops new products and services. The product variety of products is extensive, and customers have many choices. The provider is flexible and is capable of customizing its products so as to address special requests. On the other hand variation is also high; the company is not evenhanded in different processes; the lack of clear standard procedures creates inconsistent and unpredictable levels of quality of different products. Too many glitches take place. Employees try to do their best in gratifying customers but occasionally they overpromise. Customers like the product but are unsure whether they will get it or not. Much uncertainty is involved and high anxiety results (Menon \& Dube, 2000). Customers are tense and confused. The following hypotheses may be formulated: 
Hypothesis 4a. High quality of design and low quality of conformance are associated with experiencing high intensity and neutral tending towards negative valence of emotions (e.g. anxious, surprised, and confused).

Hypothesis $4 b$. High quality of design and low quality of conformance are associated with a moderate level of customer satisfaction.

The term neutral emotion used in two intermediary scenarios does not mean that a customer feels nothing. She is aroused but ambivalent about the pleasantness or unpleasantness of a particular affective state. For instance, being anxious may reflect a positive experience (e.g., a customer is anxious to try a new car) or a negative state (worry about potential losses). Confusion also results when a customer has mixed feelings in emotionally complex situations (Fong, 2006).

\section{Methodology}

\subsection{Pretest}

The purpose of the pretest is to establish respondents' perceptions of the valence and intensity of a list of eighteen externally attributed emotions developed by the researchers. This pretest was administered to a sample of 32 undergraduate college students, and it required respondents to classify each emotion as being positive (pleasant), neutral or negative (unpleasant), and as being high, moderate or low in intensity.

As a result of this pretest, the eighteen emotions were assigned to one of the nine possible categories of emotions - one for each combination of valence and intensity - based on frequency count. For instance, the majority of the students in the pretest $(72 \%)$ classified 'confused' as neutral valence/moderate intensity, and the majority $(66 \%)$ classified 'annoyed' as negative valence/low intensity. Furthermore, emotions categorized as positive, neutral and negative were assigned valences of $+1,0$ and -1 respectively. Similarly, those categorized as high, moderate and low intensity were assigned an intensity value of 3,2 and 1 respectively. Therefore, each emotion had a corresponding pair of valence and intensity values (e.g. confused $(0,2)$, annoyed $(-1,1))$. Distribution of emotions in regards to their valence and intensity is shown in Table 2 . 


\begin{tabular}{|c|c|c|c|}
\hline & Positive (+1) & Neutral (0) & Negative (-1) \\
\hline $\begin{array}{c}\text { High Intensity } \\
(\mathbf{3})\end{array}$ & $\begin{array}{c}\text { Delighted } \\
\text { Confident } \\
\text { Elated } \\
(1,3)\end{array}$ & $\begin{array}{c}\text { Surprised } \\
\text { Anxious } \\
(0,3)\end{array}$ & $\begin{array}{c}\text { Alarmed } \\
\text { Angry } \\
\text { Irate } \\
\text { Enraged }(-1,3)\end{array}$ \\
\hline $\begin{array}{c}\text { Moderate Intensity } \\
(\mathbf{2})\end{array}$ & $\begin{array}{c}\text { Comfortable } \\
\text { Content } \\
(1,2)\end{array}$ & $\begin{array}{c}\text { Confused } \\
(0,2)\end{array}$ & $\begin{array}{c}\text { Unhappy } \\
(-1,2)\end{array}$ \\
\hline $\begin{array}{c}\text { Low Intensity } \\
(\mathbf{1})\end{array}$ & $\begin{array}{c}\text { Calm } \\
(1,1)\end{array}$ & $\begin{array}{c}\text { Bored } \\
\text { Relaxed } \\
(0.1)\end{array}$ & $\begin{array}{c}\text { Annoyed } \\
\text { Apprehensive } \\
(-1,1)\end{array}$ \\
\hline
\end{tabular}

Table 2. "Distribution of emotions by their valence and intensity".

\subsection{Main Study}

After having established the perceived valence and level of intensity of each emotion in the pretest, the main study was designed to test the eight proposed hypotheses. To this end, four scenarios describing food establishments were developed, one for each possible combination of quality of design and quality of conformance (Appendix). Two samples of undergraduate college students were surveyed using two different questionnaires. The first questionnaire, completed by 103 respondents, presented two of the four scenarios: a fine dining restaurant with high design quality and high conformance quality (H1), and a hospital cafeteria with low design quality and low conformance quality (H3). The second questionnaire, completed by 77 students, presented the respondents with the remaining two scenarios: a fast-food franchise with low design quality and high conformance quality $(\mathrm{H} 2)$, and a family run diner with high design quality and low conformance quality (H4). In both questionnaires, each scenario was followed by the list of eighteen emotions, and the students were requested to select all of the emotions they are likely to experience if they were customers/patrons of the food establishment whose description they just read. Significant steps were undertaken to ensure that the four food enterprise scenarios presented to respondents were written in a manner that is descriptive and highly detailed, in an effort to simulate realistic service encounters. Furthermore, so as to establish the validity of evaluating consumer emotions in non-real situations, respondents were clearly instructed to position themselves in the customers' shoes, and imagine that they were at the receiving end of this service exchange. 
Since more than one emotion was generally indicated by respondents, each respondent acquired an emotional score, and the average valence and intensity scores were computed for each of the four scenarios. The questionnaire also included one scaled-response question measuring the extent of perceived satisfaction with the food establishment by a 5-point Likert scale (with 1 indicating high satisfaction and 5 indicating high dissatisfaction).

\section{Results}

Table 3 reports the means and standard deviations of emotions' valence and intensity, and customer satisfaction for all scenarios.

\begin{tabular}{|c|c|c|c|c|}
\hline Scenario & Statistics & Valence & Intensity & $\begin{array}{c}\text { Overall } \\
\text { Satisfaction }\end{array}$ \\
\hline \multirow{3}{*}{ 1 - High Qd/High Qc } & $\mathrm{N}$ & 98 & 98 & 97 \\
& Mean & 3.50 & 9.26 & 1.49 \\
& Std. Deviation & 1.445 & 3.384 & 0.868 \\
\hline \multirow{2}{*}{ 2 - Low Qd/High Qc } & $\mathrm{N}$ & 77 & 77 & 77 \\
& Mean & 2.04 & 6.47 & 2.38 \\
& Std. Deviation & 1.888 & 3.413 & 0.987 \\
\hline \multirow{3}{*}{ - Low Qd/Low Qc } & $\mathrm{N}$ & 98 & 98 & 97 \\
& Mean & -2.40 & 7.20 & 3.75 \\
& Std. Deviation & 1.673 & 4.074 & 0.736 \\
\hline \multirow{3}{*}{ 4- High Qd/Low Qc } & $\mathrm{N}$ & 77 & 77 & 3.10 \\
& Mean & -1.36 & 6.08 & 0.661 \\
\hline & Std. Deviation & 1.827 & 3.478 & 348 \\
& $\mathrm{~N}$ & 350 & 350 & 2.68 \\
& Mean & 0.46 & 7.37 & 1.201 \\
\hline
\end{tabular}

Table 3. "Descriptive statistics_for total valence, total Intensity and overall satisfaction across 4 scenarios".

The first set of results addresses the hypotheses that relate to the frequencies of reported emotions for each scenario ( $\mathrm{H} 1 \mathrm{a}, \mathrm{H} 2 \mathrm{a}, \mathrm{H} 3 \mathrm{a}$ and $\mathrm{H} 4 \mathrm{a})$. Tables 4 and 5 report the ANOVA and post-hoc Scheffe results for the comparison of means of valence and intensity of emotions respectively across the four scenarios.

$\mathrm{H} 1 \mathrm{a}$ pertains to the fine dining restaurant scenario, where the description exhibited high levels of quality of design and quality of conformance. It hypothesizes that students exposed to this scenario will indicate that a transaction with this food establishment will most likely elicit high intensity positive emotions. The pretest established that this category includes such emotions as delight, elation and 
confidence. Analysis of the data for this scenario resulted in a mean valence of 3.50 and a mean intensity of 9.26. Scheffe paired comparison results establish that these means are significantly greater than those of the three other scenarios ( $p$ values $<0.05$ ), supporting our hypotheses that students will express positive and high intensity emotions. In addition frequency counts and percentages for delight $78(79.6 \%)$, elation $8(8.2 \%)$, and confidence $58(59.2 \%)$ were highest among all scenarios.

ANOVA Results

\begin{tabular}{|c|c|c|c|c|c|}
\hline & Sum of Squares & df & Mean Square & F & Sig. \\
\hline Between Groups & $2,154.176$ & 3 & 718.059 & 248.776 & 0.000 \\
Within Groups & 998.681 & 346 & 2.886 & & \\
Total & $3,152.857$ & 349 & & & \\
\hline
\end{tabular}

Multiple Comparisons (Scheffe)

\begin{tabular}{|c|c|c|c|c|}
\hline $\begin{array}{c}(\mathrm{I}) \\
\text { scenario }\end{array}$ & $\begin{array}{c}(\mathrm{J}) \\
\text { scenario }\end{array}$ & $\begin{array}{c}\text { Mean } \\
\text { Difference } \\
(\mathrm{I}-\mathrm{J})\end{array}$ & Std. Error & Sig. \\
\hline \multirow{3}{*}{1} & 2 & $1.461\left(^{*}\right)$ & 0.259 & 0.000 \\
& 3 & $5.898\left(^{*}\right)$ & 0.243 & 0.000 \\
& 4 & $4.864\left(^{*}\right)$ & 0.259 & 0.000 \\
\hline \multirow{2}{*}{3} & 1 & $-1.461\left(^{*}\right)$ & 0.259 & 0.000 \\
& 3 & $4.437\left(^{*}\right)$ & 0.259 & 0.000 \\
& 4 & $3.403\left(^{*}\right)$ & 0.274 & 0.000 \\
\hline & 1 & $-5.898\left(^{*}\right)$ & 0.243 & 0.000 \\
& 2 & $-4.437\left(^{*}\right)$ & 0.259 & 0.000 \\
& 4 & $-1.034\left(^{*}\right)$ & 0.259 & 0.001 \\
\hline & 1 & $-4.864\left(^{*}\right)$ & 0.259 & 0.000 \\
& 2 & $-3.403\left(^{*}\right)$ & 0.274 & 0.000 \\
& 3 & $1.034\left(^{*}\right)$ & 0.259 & 0.001 \\
\hline
\end{tabular}

$*$. The mean difference is significant at the .05 level.

Table 4. "Comparison of means (ANOVA) for valence across 4 scenarios".

$\mathrm{H} 2 \mathrm{a}$ proposes that the fast-food franchise scenario with low quality of design and high quality of conformance will bring out low intensity, neutral/positive emotions such as boredom and relaxation. Our results indicate a mean valence of 2.04 and a mean intensity of 6.47 for this scenario. Scheffe tests establish that the valence value is significantly different from that of the other three scenarios ( $p$-values $<0.05)$, and corresponds with our prediction that these emotions tend to be neutral or somewhat positive. The intensity value 6.47 is the second lowest among four scenarios and is significantly lower than the previous scenario. In addition reported 
frequency counts and percentages of boredom $13(16.9 \%)$ are the highest across scenarios, and relaxation $29(37.7 \%)$ are the second highest frequency for this emotion after scenario four. These results generally support our predictions.

ANOVA Results

\begin{tabular}{|c|c|c|c|c|c|}
\hline & Sum of Squares & df & $\begin{array}{c}\text { Mean } \\
\text { Square }\end{array}$ & F & Sig. \\
\hline Between Groups & 542.212 & 3 & 180.737 & 13.819 & 0.000 \\
Within Groups & $4,525.242$ & 346 & 13.079 & & \\
Total & $5,067.454$ & 349 & & & \\
\hline
\end{tabular}

Multiple Comparisons (Scheffe)

\begin{tabular}{|c|c|c|c|c|}
\hline $\begin{array}{c}(\mathrm{I}) \\
\text { Scenario }\end{array}$ & $\begin{array}{c}(\mathrm{J}) \\
\text { Scenario }\end{array}$ & $\begin{array}{c}\text { Mean } \\
\text { Difference }(\mathrm{I}-\mathrm{J})\end{array}$ & Std. Error & Sig. \\
\hline \multirow{3}{*}{1} & 2 & $2.788\left(^{*}\right)$ & 0.551 & 0.000 \\
& 3 & $2.051\left(^{*}\right)$ & 0.517 & 0.001 \\
& 4 & $3.177\left(^{*}\right)$ & 0.551 & 0.000 \\
\hline \multirow{2}{*}{3} & 1 & $-2.788\left(^{*}\right)$ & 0.551 & 0.000 \\
& 3 & -0.737 & 0.551 & 0.618 \\
& 4 & 0.390 & 0.583 & 0.930 \\
\hline \multirow{3}{*}{4} & 1 & $-2.051\left(^{*}\right)$ & 0.517 & 0.001 \\
& 2 & 0.737 & 0.551 & 0.618 \\
& 4 & 1.126 & 0.551 & 0.244 \\
\hline & 1 & $-3.177\left(^{*}\right)$ & 0.551 & 0.000 \\
& 2 & -0.390 & 0.583 & 0.930 \\
\hline
\end{tabular}

*. The mean difference is significant at the .05 level.

Table 5. "Comparison of means (ANOVA) for intensity across 4 scenarios".

$\mathrm{H} 3 \mathrm{a}$ predicts that the emotions most likely elicited by the hospital cafeteria scenario (low on both dimensions) are ones that were classified by the pretest as being negative and highly intensive (alarm, anger, ire and rage). The valence and intensity values for this scenario are -2.40 and 7.20 respectively. Scheffe paired comparisons establish that the valence value is significantly lower from that of the other three scenarios ( $p$-values $<0.05$ ), and corresponds with our prediction that these emotions are negative. Intensity value is the second highest among four scenarios, significantly higher than in the last scenario ( $p$-value $<0.05$ ), but not significantly higher than in the previous one. In addition the frequency counts and percentages for alarm $14(14.3 \%)$, anger $42(42.9 \%)$, ire $25(25.5 \%)$, and rage 11 $(11.2 \%)$ are the highest reported across the four scenarios. These results partially support our hypothesis. 
Finally, $\mathrm{H} 4 \mathrm{a}$ looks at the last scenario for a family run diner with high design quality and low conformance quality. Students reading this scenario were expected to indicate neutral/negative emotions with high intensity, such as surprise, anxiety and confusion. Results indicate a mean valence of -1.36 which is the second lowest among four scenarios. As far as intensity goes, the mean intensity is 6.08 , which, contrary to predictions, is not high, but rather the lowest reported mean intensity among the four scenarios. These results do not support our hypothesis. At the same time the frequency counts and percentages for respondents being surprised and anxious as $17(22.1 \%)$ and $8(10.4 \%)$ respectively are highest across all four scenarios, and confused (32 and $41.6 \%$ ) is the second highest frequency for this emotion after scenario three; this provides certain support for predicted pattern.

ANOVA Results

\begin{tabular}{|c|c|c|c|c|c|}
\hline & $\begin{array}{c}\text { Sum of } \\
\text { Squares }\end{array}$ & df & Mean Square & F & Sig. \\
\hline Between Groups & 268.751 & 3 & 89.584 & 133.086 & 0.000 \\
Within Groups & 231.556 & 344 & 0.673 & & \\
Total & 500.307 & 347 & & & \\
\hline
\end{tabular}

Multiple Comparisons (Scheffe)

\begin{tabular}{|c|c|c|c|c|}
\hline $\begin{array}{c}(\mathrm{I}) \\
\text { Scenario }\end{array}$ & $\begin{array}{c}(\mathrm{J}) \\
\text { Scenario }\end{array}$ & $\begin{array}{c}\text { Mean } \\
\text { Difference } \\
(\mathrm{I}-\mathrm{J})\end{array}$ & Std. Error & Sig. \\
\hline \multirow{3}{*}{1} & 2 & $-.88\left(^{*}\right)$ & 0.125 & 0.000 \\
& 3 & $-2.25\left(^{*}\right)$ & 0.118 & 0.000 \\
& 4 & $-1.609\left(^{*}\right)$ & 0.125 & 0.000 \\
\hline \multirow{2}{*}{3} & 1 & $.882\left(^{*}\right)$ & 0.125 & 0.000 \\
& 3 & $-1.376\left(^{*}\right)$ & 0.125 & 0.000 \\
& 4 & $-.727\left(^{*}\right)$ & 0.132 & 0.000 \\
\hline \multirow{3}{*}{3} & 1 & $2.258\left(^{*}\right)$ & 0.118 & 0.000 \\
& 2 & $1.376\left(^{*}\right)$ & 0.125 & 0.000 \\
& 4 & $.649\left(^{*}\right)$ & 0.125 & 0.000 \\
\hline & 1 & $1.609\left(^{*}\right)$ & 0.125 & 0.000 \\
& 2 & $.727\left(^{*}\right)$ & 0.132 & 0.000 \\
& 3 & $-.649\left(^{*}\right)$ & 0.125 & 0.000 \\
\hline
\end{tabular}

$*$. The mean difference is significant at the .05 level.

Table 6. "Comparison of means (ANOVA) for overall satisfaction across 4 scenarios".

The second set of results looks at the hypotheses examining the relationship between levels of quality of design and conformance and perceived customer satisfaction ( $\mathrm{H} 1 \mathrm{~b}, \mathrm{H} 2 \mathrm{~b}, \mathrm{H} 3 \mathrm{~b}$ and $\mathrm{H} 4 \mathrm{~b}$ ). A one-way ANOVA comparing the means for 
the Satisfaction ratings across the four scenarios indicated significantly different means ( $p$-values <0.05).

A closer inspection of these differences, through post-hoc Scheffe tests lends support to all four hypotheses, indicating that high levels of both quality dimensions are associated with significantly greater customer satisfaction. Both the low design quality and high conformance quality (fast-food franchise) scenario and opposite combination (family-run diner) resulted in moderate levels of satisfaction of 2.38 and 3.10 respectively. Finally the hospital cafeteria scenario (corresponding to low levels of both quality dimensions) resulted, as expected, in the lowest level of satisfaction (3.75).

\section{Discussion}

In this paper we study the links between quality and consumers' emotions and eventually with their satisfaction. Our contribution hinges on applying two dimensions of quality that were not used in this field before - quality of design and conformance. Most of hypothesized links were confirmed statistically. The results show that there is a significant relationship between possible combinations of two quality dimensions and customers' affective responses regarding their valence and intensity.

Our results indicate that when both quality of design and conformance are high, customers tend to experience positive emotions with high intensity. As was expected their satisfaction is highest of all four scenarios. In the opposite situation when both dimensions are low, customers tend to respond with negative and intensive emotions, and satisfaction is the lowest. One hypothesis that was not supported empirically referred to the last scenario with high quality of design and low quality of conformance. We expected that this combination would generate emotions with high intensity and neutral/negative valence. In fact we received responses with lowest intensity and rather high unpleasantness. A possible explanation, which should be tested in future research, is that mixed messages sent by a provider engender an array of various emotions among different customers, and the overall result is lack of intensity in affective response.

An interesting finding of this study suggests that customers value quality of conformance higher than quality of design. In two intermediate scenarios when one 
of components is low and the other is high, emotions were quite different. When quality of conformance is high and quality of design is low, affective responses are characterized by somewhat positive valence and low intensity. In the opposite combination customers experience negative emotions with low arousal. Customers' satisfaction was significantly higher in the former case.

Our findings have important managerial implications. Existing literature pays considerable attention to coping with customers' emotional responses. Several studies stress the importance and contain valuable recommendations regarding training employees in diagnosing and responding appropriately to customers' emotions. These steps allow preventing negative behaviors of customers such as switching, negative word-of-mouth, complaining etc. (Menon \& Dube, 2000; Bougie et al., 2003; Smith \& Bolton, 2002). Much less is said about analysis of internal causes and processes that generate affective reactions. Recommendations regarding service delivery improvement and recovery processes directed at emotional situation of customers are rather general and do not provide managers with specific guidelines about problematic areas in company's activities (see, e.g. Smith \& Bolton, 2002: 19-20). This reflects separation of marketing and quality management literature. Customer emotions are analyzed by marketing researchers, whose specialization does not embrace internal operations. We argue that consumer's emotions should be treated as symptoms of problems embedded in organizational processes. Though it is important to train associates to decode emotional expressions and adequately react to them, it is by no means sufficient. This would leave us with coping with symptoms alone, without analyzing deeper roots of problems. Merit of emotions as symptoms lies in exposing organizational "diseases" that otherwise would stay unrecognized.

Our model allows pinpointing elements of quality that pose weaknesses and should be "cured". For instance, if customers experience strong negative emotions such as anger or ire, a provider can reasonably conclude that both quality of design and conformance are on inadequate levels and need to be improved. If customers express anxiety, then quality of conformance is unsatisfactory. In both cases since quality of conformance is an issue, a company should be engaged in activities described in TQM literature (see e.g. Deming, 1986; Juran, 1989) aimed at reduction of variation in its processes. The first step has to be eliminating special causes of variation and bringing a process into a state of statistical control, where 
variation is kept within control limits. The next and more profound step involves analyzing common causes of variation so as to decrease the range between control limits and continuously enhance process capability.

In a situation when emotions experienced by customers are positive but not intense a provider should infer that a company does not have serious problems with conformance quality and high variation, therefore it should not invest abundant resources in improving this element of quality. What it should concentrate on is quality of design - "fine tuning" of products and services to customer needs, increasing variety and flexibility in service delivery. More effort should be spent on marketing and R\&D activities such as customer research, sales/service call analysis etc. (Gitlow et al., 2005: 21-22). Therefore observing certain emotion managers can trace its origin to particular combination of quality dimensions and then proceed searching for root causes of quality problems.

Our findings can be also applied in a more proactive way. By making improvements in certain quality elements, managers can predict what emotional responses will ensue. The appearance of anticipated emotions in reality will be a valid sign that quality improvement in fact took place. For instance, when already content customers as a result of organizational measures become even more delighted, the implication is that the quality of design has improved. The overall schema for managerial actions regarding customer emotions will be the following (figure 1 ):
Initial emotions as $\rightarrow$ signals of quality issues
Improvement of relevant quality elements
$\rightarrow \quad$ Resulting emotions

Figure 1. "Overall schema for managerial actions".

\section{Conclusion and future research}

Our results suggest a significant relationship between quality, customer emotions and satisfaction. A question arises concerning the direction and character of this relationship. Yiang and Cheng (2006) argue that affect precedes quality perceptions. On the other hand Oliver (1993) found that emotions mediate the link between quality and satisfaction, which means that quality precedes emotions. Along these lines Dube and Menon (2000) and Price et al. (1995) also maintain 
that consumers' emotions mediate the link between a provider's performance and their satisfaction. If we replace performance with quality then this line of reasoning brings us to a proposition that emotions play a mediating role between quality and satisfaction. Our study was designed in such a way that participants had to respond with certain emotions to predetermined combinations of quality dimensions. This also suggests that affect follows quality. However because we used fixed scenarios and did not quantitatively measure quality components, our method and results cannot lead to definite conclusions regarding the character of discussed link. This limitation clearly demarcates the venue for the future research.

Another concern is that the empirical study utilizes a methodology that assesses consumer emotion in a non-real service situation. We undertook certain steps to increase the validity of our methodology, namely scripting highly descriptive food enterprise scenarios, and clearly instructing our respondents to position themselves at the receiving end of the described service exchange. Still, this point represents a limitation and an opportunity for future research where this study could be replicated with real consumers encountering actual service situations. Another limitation of this study is that it investigates customer responses in only one industry, which limits applicability of the generalizations garnered from the results. Future research should address this limitation by taking into account different contexts, e.g. utilitarian versus hedonic consumption which may have considerable effect on the relationship between perceived quality and customers' emotions.

\section{Appendix}

Scenario 1 - High quality of design/High quality of conformance_- Fine dining restaurant

Cappelli Bistro is a fine dining establishment located in the downtown area of a small suburban town. They offer a considerable variety of appetizers, entrees, desserts on their menu along with an impressive wine selection. Cappelli Bistro prides itself on continuously updating their menu, and adding seasonal specialties to it. The restaurant is owned and operated by members of the Cappelli family, and it employs twelve servers and bar attendants. Cappelli Bistro has been very successful at responding to patrons' special dietary needs and requests, and consumers agree that the management and staff are quite consistent in providing service, handling orders and billing, which results in a negligible number of 
consumer complaints. Repeat customers depend on the personnel to provide reliable service, and they feel comfortable knowing what to expect when dining at Cappelli Bistro, and that management and staff always deliver on their promises. In addition to the enjoyment that diners get from the rich assortment of good quality food, and the possibility of personalizing their orders, they also appreciate that the service at Cappelli Bistro is dependable.

Scenario 2 - Low quality of design/High quality of conformance - Fast-food franchise

Zippy is a fast-food franchise with over 30 branches located throughout New England. They offer a standardized, limited menu consisting mainly of sandwiches and sides - they have been serving all of these items for many years. They focus their efforts on providing fast meals and therefore offer no-frills, basic items without accommodating any specific dietary needs and requests, since they believe in a one-size fits all philosophy. Consumers agree that the management and staff are quite consistent in providing service, handling orders and billing, which results in few mistakes and a negligible number of consumer complaints. Repeat customers know exactly what to expect when eating at Zippy, and management and staff always deliver on their promises. Despite the limited choice of mediocre quality items on the menu, patrons appreciate that the service at Zippy is always predictable.

Scenario 3 - Low quality of design/Low quality of conformance - Hospital cafeteria

Stafford is a hospital cafeteria in a small suburban town. They offer a standardized limited menu consisting mainly of sandwiches, soups, salads and sides - all items that they have been serving for many years. They focus their efforts on providing fast meals and therefore offer no-frills, basic items without accommodating any specific dietary needs and requests.

Stafford is run mostly by part-time employees who attend the local college. These employees rotate between food preparation and service. Because of this steady stream of new food preparers and servers, consumers complain that they get different answers to the same question from different employees. Patrons find that service at Stafford is quite unpredictable, mainly due to the inconsistent and erratic behavior across personnel, and they find it hard to agree on how they assess or 
rate this food establishment. Also, there have been repeated incidents of consumers receiving the wrong order or having errors in their bills, which results in a high rate of consumer complaints.

Scenario 4 - High quality of design/Low quality of conformance-Family-run diner

Gino's is a family-run diner in a small suburban town. They offer a considerable variety of items on their menu, as well as a range of services including take-out, delivery and catering. Gino's prides itself on continuously updating their menu, and adding seasonal specialties to it. Gino's is run mostly by family members and two part-time employees who attend the local college. Although Gino's has been very successful at responding to their special dietary needs and requests, consumers still complain that they get different answers to the same question from different employees. Also, there have been repeated incidents of consumers receiving the wrong order or having errors in their bills, which results in a high rate of consumer complaints. Despite the enjoyment that diners get from the rich assortment of good quality food, and the possibility of personalizing their orders, they find that service at Gino's is quite unpredictable, mainly due to the inconsistent and erratic behavior across personnel. Patrons of Gino's find it hard to agree on how they assess or rate this food establishment.

\section{References}

Bagozzi, R.P., Gopinath, M., \& Nyer, P.U. (1999). The Role of Emotions in Marketing. Journal of the Academy of Marketing Science, 27(2), 184-206.

Bougie, R., Pieters, R., \& Zeelenberg, M. (2003). Angry Customers Don't Come Back, They Get Back: The Experience and Behavioral Implications of Anger and Dissatisfaction in Services. Journal of the Academy of Marketing Science, 31(4), 377-393.

Boulding, W., Kalra, A, Staelin R., \& Zeithaml, V.A. (1993). A Dynamic Process Model of Service Quality: From Expectations to Behavioral Intentions. Journal of Marketing Research, 30 (February), 7-27.

Cronin, J. J., \& Taylor, S. A. (1992). Measuring Service Quality: A Reexamination and Extension. Journal of Marketing, 56(3), 55-68. 
Cronin, J. J., \& Taylor, S. A. (1994). SERVPERF versus SERVQUAL: Reconciling Performance-Based and Perceptions Minus Expectations Measurement of Service Quality. Journal of Marketing, 58(1), 125-131

Deming, W.E. (1986). Out of Crisis. Cambridge, MA: M.I.T. Center for Advanced Engineering Studies.

Dube, L., \& Menon, K. (2000). Multiple Roles Of Consumption Emotions In PostPurchase Satisfaction With Extended Service Transaction. International Journal of Service Industry Management, 11(3), 287-304.

Finn, A. (2005). Reassessing Foundations of Customer Delight. Journal of Service Research, 8(2), 103-116.

Fong, C.T. (2006). The Effects of Emotional Ambivalence on Creativity. Academy of Management Journal, 49(5), 1016-1030.

Gitlow, H.S., Oppenheim, A.J., Oppenheim, R., \& Levine, D.M. (2005). Quality Management. 3rd Edition., Boston: McGraw-Hill.

Jiang, Y., \& Wang C.L. (2006). The Impact of Affect on Service Quality and Satisfaction: The Moderation of Service Contexts. Journal of Services Marketing, 20(4), 211-218.

Juran, J.A.M. (1989). Juran on Leadership for Quality. New York: Free Press.

Kano, N., Seraju, N., Takahashi, F., \& Tsuju, S. (1984). Attractive Quality and Must-Be Quality, Hinshitzu, The Journal of the Japanese Society for Quality Control, 14 (April), 39-48.

Kramph, R., Ueltschy, B., \& d'Amico, M. (2002). The Contribution of Emotion to Consumer Satisfaction in the Service Setting. The Marketing Management Journal, $13(1), 32-52$.

Kumar, A., Olshavsky, R.W., \& King, M.F. (2001). Exploring Alternative Antecedents of Customer Delight. Journal of Consumer Satisfaction, Dissatisfaction and Complaining Behavior, 14, 14-26. 
Liljander, V., \& Strandvik, T. (1997). Emotions in Service Satisfaction. International Journal of Service Industry Management, 8(2), 148-169.

Mano, H., \& Oliver, R.L. (1993). Assessing Dimensionality and Structure of the Consumption Experience: Evaluation, Feeling, and Satisfaction. Journal of Consumer Research, 20(December), 451-466.

Mattsson, J., Lemmink, J., \& McColl (2004). The Effect of Verbalized Emotions on Loyalty in Written Complaints. Total Quality Management, 15(7), 941-958.

Meirovich, G. (2006). Quality of Design and Quality of Conformance: Contingency and Synergistic Approaches. Total Quality Management and Business Excellence, $17(2), 205-220$.

Menon, K., \& Dube, L. (2000). Ensuring Greater Satisfaction by Engineering Salesperson Response to Customer Emotions. Journal of Retailing, 76(3), 285307.

Oliver, R.L. (1981). Measurement and Evaluation of the Satisfaction Process in Retail Settings. Journal of Retailing, 57(3), 25-48.

Oliver, R.L. (1993a). Cognitive, Affective and Attribute Bases of the Satisfaction Response. Journal of Consumer Research, 20(3), 418-430.

Oliver, R.L. (1993b). A Conceptual Model of Service Quality and Service Satisfaction: Compatible Goals, Different Concepts. In A.T. Swartz, D.E. Bowen, \& S.W. Brown (Eds), Advances in Services Marketing Management (pp 65-85). Greenwich, CT: JAI Press Inc.

Oliver, R.L. (1996). Satisfaction: A Behavioral Perspective on the Consumer. New York: McGraw-Hill.

Oliver, R.L., \& Westbrook R.A. (1993). Profiles of Consumer Emotions and Satisfaction in Ownership and Usage. Journal of Consumer Satisfaction, Dissatisfaction and Complaining Behavior, 6, 12-27.

Parasuraman, A., Zeithaml V., \& Berry L. (1991) Refinement and Reassessment of SERVQUAL Scale. Journal of Retailing, 67(4), 420-450. 
Peter J.P., Churchill, G.A., \& Brown, T.J. (1992). Caution in the Use of Difference Scores in Consumer Research. Journal of Consumer Research, 19(March), 655662.

Price, L. L., Arnould, E. J., \& Tierney, P. (1995). Going to Extremes: Managing Service Encounters and Assessing Provider Performance. Journal of Marketing, 59(2), 83-97.

Russell, J.A. (1980). A Circumplex Model of Affect. Journal of Personality and Social Psychology, 39(6), 1161-1178.

Smith, A.K., \& Bolton, R.N. (2002). The Effect of Customers' Emotional Responses to Service Failures on Their Recovery Effort Evaluations and Satisfaction Judgments. Journal of the Academy of Marketing Science, 30(1), 5-23.

Teas, K. (1993). Expectations, Performance Evaluation, and Consumers' Perceptions of Quality. Journal of Marketing, 57(4), 18-35.

Widrick, S.M., Mergen, E., \& Grant D. (2002). Measuring the Dimensions of Quality in Higher Education. Total Quality Management, 13(1), 123-131. 